\title{
Performance Analysis of Multinational M\&A of Listed Companies--Based on Zipf Stock Price-Fundamentals Dynamic Evaluation Model's Construction
}

\author{
Wenjie Liu $^{1}$ \\ ${ }^{1}$ School of Economics, Beijing Technology and Business University, China \\ Correspondence: Wenjie Liu, School of Economics, Beijing Technology and Business University, Beijing, China. \\ Tel: 188-1135-9099. E-mail: dgliuwenjie@163.com
}

Received: May 13, 2018

Accepted: May 29, 2018

Online Published: June 5, 2018

doi:10.5539/ijef.v10n7p64

URL: https://doi.org/10.5539/ijef.v10n7p64

\begin{abstract}
In this paper, the multinational M\&A of listed companies are taken as the research objects. The Stock Price-Fundamentals Dynamic Evaluation Model (SF-DEM) based on Zipf's law is constructed. Through the complementary cumulative distribution, we analyze the stock price and fundamentals distribution and changes of listed companies before and after multinational M\&A. The two-way fixed effect model is introduced to verify the SF-DEM model. The research shows that multinational M\&A have got a positive response from the market. Short-term average cumulative abnormal rate of return reached $2.8 \%$ after the announcement day, which had a long-term synergy and promoted companies' value; As investors expected that high-priced stocks have a poorer growth and higher thresholds, multinational M\&A have a significant and lasting effect on the low-priced companies, while the impact on high-priced stocks is small and short; $80 \%$ of the price changes were determined by fundamentals, and reached $85 \%$ after M\&A. Multinational M\&A enhances investors' expectations and then shows the value investment trends. 80/20 law is not affected by M\&A, companies have strong heterogeneity and large differences.
\end{abstract}

Keywords: Zipf's law, multinational M\&A, stock price, fundamentals, SF-DEM

\section{Introduction and Literature Review}

In recent years, multinational M\&A have shown a momentum of rapid growth. However, multinational M\&A are subject to many uncertainties due to the complexity of political, economic, legal, cultural factors and operations, as well as the competition for interests and compromises. Revealing the inherent laws in the process of M\&A and studying its impact on the development of the companies have became a concern of some scholars. Most scholars use event study method and financial data method to analyze the short-term and long-term performances of multinational M\&A in order to provide strategic advice. Bill (2008) discussed the impact of U.S. companies before and after M\&A and found that they have achieved market excess returns and performance rewards; Nam-Hoon (2000) believes that complementary technologies, human resources, and brand effects are the reasons for multinational M\&A, benefits are the result of it; Xiaoting (2004) compared and analyzed the motivations of M\&A in China and the United States and found that China's M\&A have limited the market role of survival of the fittest due to improper government intervention; Lihong (2016) believes that cognitive and cultural conflicts have limited the integration of M\&A companies' culture; Xinjian (2012) analyzed the M\&A performance of A-share listed companies and found that the cumulative abnormal return rate near the announcement day reached $5.2 \%$, reflecting the positive attitude of investors towards M\&A.

The short-term performance of M\&A is reflected in the change of stock price rate of returns, and long-term performance is reflected in fundamentals changes. However, there are few literatures that have combined the stock price and fundamentals changes rules to judge the effectiveness of M\&A. The domestic scholars' studies on the relationship between stock prices and fundamentals only focuse on the degree of deviation. Shuyun (2001) based on the regression to measure the influence of the fundamentals changes on the stock price to judge the speculative components of China's stock market, and drew a conclusion that speculative bubbles in the bull market accounted for 70\% in 1999; Xi (2011) introduced a neural network model to analyze and predict the relationship between stock price and fundamentals, believing that the stock price of listed companies is gradually moving towards 
fundamentals; Ziyuan (2010) uses structural models to explore the relationship of stock price fluctuations and fundamentals risks, and found that the two were deviated in the bull market, and had a positive correlation in the bear market. Ankang (2003) analyzed the characteristic factors of the Shanghai Stock Exchange Index based on the GARCH model and obtained the conclusion that the rate of return has a positive relationship with the profitability index in the company's fundamentals. In relevant foreign references, Jeffrey (2017) proved the close correlation between U.S. stock price and fundamentals changes, and the reason is that investors believe that accounting earnings are risk-free and therefore tend to value investing; Refet (2008) proposed that the stock price bubble test failed to recognize the existence of bubble for abnormal stocks; Louis (1991) conducted an in-depth study of the Japanese stock market and found that the stock price and fundamentals fluctuate positively.

According to the EMH hypothesis, the market price of financial products have already contained all the information. Therefore the stock price is closely related to its value in the mature stock market; While the A-share market has long been considered having large number of retail investors, few institutions. The information asymmetry has led to price distortions and bubbles, then have been believed that price deviated from the fundamentals. Will it change the performance of China's stock market investment due to the multinational M\&A which combines two or more countries with different styles of markets? What is the impact on multinational M\&A companies and stock market participants?

This paper introduces Zipf's law to study the distribution and changes of stock price and fundamentals. Analyze the reasons for the their changes before and after multinational M\&A based on the two-way fixed effect model. Introducing the probability model into the securities field solves the Zipf empirical test, explaines the significance of their distributions and makes up for the gap in domestic literature. This research will help listed companies formulate a reasonable overseas expansion strategy. It also has certain reference significance for the government to formulate relevant overseas M\&A policies and promote the development of the securities market and industry.

\section{Model and Data}

Zipf's law originated from linguistic metrology. It is originally used to describe the relationship between rankings and frequency of word. It has been applied in many fields these years such as informatics, economics, sociology, biology, geography, and so on. Li (1999), Cancho (2003), Wenxia (1986) further explored the law of word frequency and extended the applicable mechanism of Zipf's law; Lada (2002), Cunha (1995), Shengjiu (2015) studied the trajectory of Internet access frequency based on Zipf's law; Xavier (1999), Guangzhou (2017) analyzed the Zipf distribution of the city scale and revealed different cities have differentiated development; Israeloff (1996), Yujian (2005) applied Zipf's law to the biological field; Robert (2001), Julian (2013) obtained the distribution characteristics of company size based on Zipf's law; Zhenhua (2012) established a dynamic model of carbon price changes and analyzed the fluctuation and risk mechanism of carbon price. Generalized Zipf is defined as:

$$
R^{\alpha} \times P=C
$$

Among them, $\mathrm{R}$ is the word ranking, $\mathrm{P}$ is the frequency of word, $\alpha$ is the power law index, and $\mathrm{C}$ is the constant.

In the field of finance, the study of normal distribution in the power law theory has been quite rich. However, the application of Zipf's law with long-tailed distribution still remains at the empirical test stage and don't analyze the reason and practical significance of the law. Jun (2007) used the complementary cumulative distribution function to study the Zipf distribution statistical characteristics of the closing price of A shares; Taisei (2004) analyzed the stock prices of the Tokyo Stock Exchange and confirmed that the stock price distribution follows Zipf's law; He also found that trading volumes were volatile based on the Zipf distribution, and the stock price volatility performance was not significant (Taisei, 2016).

This paper establishes the SF-DEM model based on Zipf's law. It is hoped to reveal the internal laws of stock price and fundamentals changes caused by multinational M\&A, and explore the reasons for the changes.

Converting the Zipf's law, we get the complementary cumulative distribution probability of stock price and fundamentals $\mathrm{P}, \mathrm{x}$ is the stock price and fundamentals data and $\alpha$ is the power law index, they are expressed as follows:

$$
P(\mathrm{X}>\mathrm{X})=\mathrm{C} \times \mathrm{R}^{-\alpha}
$$

Using MLE to calculate the power law index in complementary cumulative distribution function. The Pareto distribution probability density function is:

$$
f(x)=\frac{\alpha y^{\alpha}}{S_{i}^{\alpha+1}} \quad(0 \leq \mathrm{y} \leq \mathrm{S})
$$


Among them, $S_{i}$ is the stock price. When $y=S_{\min }$, MLE is:

$$
\hat{\alpha}=\frac{n}{\sum_{i=1}^{n} \ln \frac{S_{i}}{S_{\text {m i n }}}}
$$

We find Cramer-von Mise power law goodness-of-fit test is most effective by using Monte-Carlo testing, and use the K-S test for auxiliary testing. Then using the L-M test and L-R test to verify whether the stock price and the fundamentals distribution are Zipf distributions and discuss the relationship between the two based on the distributions and changes.

The data used in this paper comes from the Zephry database, the RESSET database and the CSMAR database. The object is 164 multinational M\&A A-share listed companies' (excluding ST shares, *ST shares, S*ST shares) 237 mergers and acquisitions activities from 2003 to 2016; The specific data includes the daily stock price and financial indicators for each year before and after company's M\&A announcement day. We get 21 days of stock price return, Shanghai Composite Index's return and Shenzhen Stock Index's return before and after the M\&A announcement day. Among them, we select the restoration of the right price as stock price to eliminate the issue caused by dividends and share donation. The earnings per share, net assets per share and operating income per share are selected as financial basic indicators (Kaizoji, 2004). Using Matlab, SPSS, Eviews, and R to perform data processing and model validation.

\section{The Realization of SF-DEM Model Based on Zipf's Law}

First, verify whether the stock price follows the power law distribution before and after M\&A and observe the changes in the stock price due to it; According to the changes to classify the stock price, using event study method to explore the reasons; Then analyze the relationship of the stock price and the fundamentals and the reasons for the relationship changes based on the panel data model; Finally, use the Zipf distribution to verify the relationship between the stock price and the fundamentals.

\subsection{Zipf Distribution before and after M\&A}

The results of the daily restoration of the right price complementary cumulative distribution before and after M\&A of the listed companies are shown in Figures 1 and 2, in which the stock price is taken as a logarithm, as a total of 51,754 observations before the M\&A, and54,555 after the M\&A. From Figure 1 and2, it can be seen that the right tail are linearly distributed. It can be inferred that the stock price follows the Zipf distribution before and after the M\&A. After the M\&A, the stock price has generally improved, the low-priced stocks have changed significantly, and the high-priced stocks have not changed much.

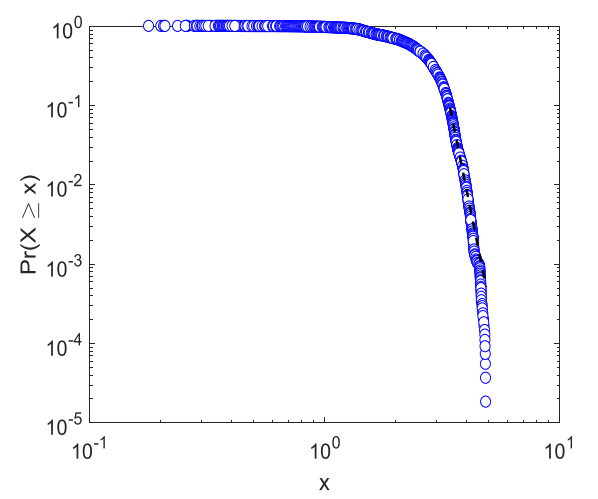

Figure 1. CCD of stock price before M\&A

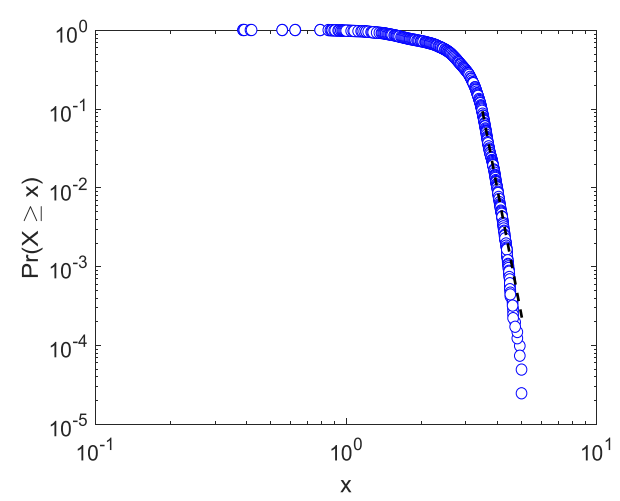

Figure 2. CCD of stock price after M\&A

From eq.3, the power-law exponent $\alpha$ is 0.440 before M\&A and 0.466 after M\&A. Then test whether the cumulative distribution of the stock price follows the power law distribution. The results are shown in Table 1.

Table 1. Test results of stock price distribution before and after M\&A

\begin{tabular}{ccccc}
\hline$\alpha$ & Crmer-vonMise (p-value) & K-S (p-value) & L-M (p-value) & L-R (p-value) \\
\hline 0.440 & 0.142 & 0.000 & 0.000 & 0.000 \\
0.466 & 0.157 & 0.000 & 0.008 & 0.000 \\
\hline
\end{tabular}


From the results, we can see that the stock price before and after the M\&A both passed the power law distribution goodness-of-fit test and Zipf's law test. M\&A did not change the applicability of Zipf's law to the stock price, and only changed the power law index and the complementary cumulative distribution function graph. What are the reasons for the low-priced stock increase aparently and the high-priced stocks are not?

\subsection{Event Study Framework and Results Analysis}

Explain the reasons for the inconspicuous increase in high-priced stock by the change of investors' expectations in the M\&A behavior which is overall good. The event study method was introduced to calculate and analyze the cumulative abnormal rate of return.

\subsubsection{Event and Window Definitions}

The first announcement of multinational M\&A was selected as the event. The first announcement day was 0 day. Referring to the selection of the event window by Xinjian (2012), consider the information leakage and the statistical significance of AR analysis results, we select the total of 21 days before and after the announcement day as an event window. Define the data of the top $10 \%$ of the company’s restoration of the right price (>¥32.5) as high-priced stock.

\subsubsection{Average Cumulative Abnormal Rate of Return Estimate}

China's $\beta$ value varies greatly every day and is extremely sensitive to the choice of window period (Xinjian, 2012), abandoning the market model method commonly used at home and abroad and choose the Shanghai Stock Index return and the Shenzhen Stock Index return as the normal rate of return.

$$
A R_{i t}=\mathrm{R}_{i t}-\mathrm{R}_{m t}
$$

$\mathrm{AR}_{\mathrm{it}}$ is an abnormal rate of return, $\mathrm{R}_{\mathrm{it}}$ and $\mathrm{R}_{\mathrm{mt}}$ are the actual rate of return and the market index rate of return. $\sum_{t=\varphi_{1}}^{\varphi_{2}} A R_{i t}$

represents the accumulative abnormal rate of return, the $\varphi_{1}$ and $\varphi_{2}$ represents the start and end time of the window period, $\overline{C A R}$ is expressed as:

$$
\overline{C A R}\left(\varphi_{1}, \varphi_{2}\right)=\frac{1}{n} \sum_{i=1}^{n} \sum_{t=\varphi_{1}}^{\varphi_{2}} A R_{i t}
$$

\subsubsection{Results Analysis}

After the event study on the overall and high-priced stocks, results were shown in Figure 3. It was evident that the overall stock price made a positive market reaction on the six trading days before the announcement day, indicating that information leaked before announcement of the M\&A, leading investors to take action in advance.

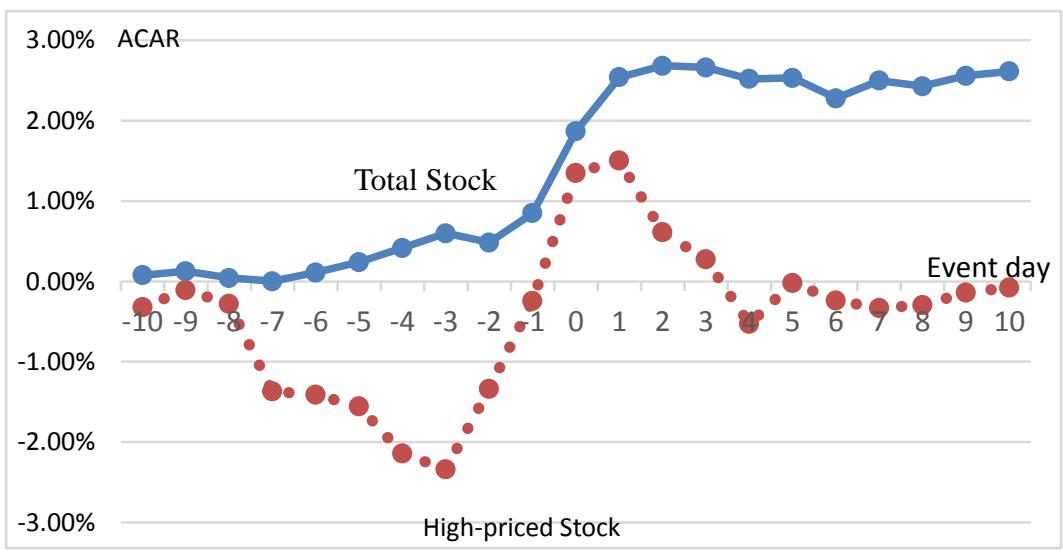

Figure 3. Distribution of ACAR of overall and high-priced stocks

CAR in Figure 3 shows an upward trend during the $(-6,10)$ window period, with the $(-1,1)$ window growing fastest, rising by $1.2 \%$ and $0.8 \%$, and both passing the $\mathrm{J}$ statistic significance. The test shows that the multinational M\&A has an overall positive effect, it has win the approval of investors. Because investors expect that M\&A will have a positive effect and are reflected in market reactions. However, the performance of high-priced stock is unsatisfactory. Before the announcement, its average cumulative abnormal rate of return 
continued to decline for 5 days, although it increased during the window period $(-3,1)$ and generated an average cumulative abnormal rate of return of $1.3 \%$ at the announcement day, but it quickly fell negative until it reached the level of market returns. This paper believes that on the one hand high-priced stocks have experienced a period of rapid growth, while M\&A behavior embodied as a temporary arbitrage speculation, but for low-priced stock, M\&A can help improving the company's intrinsic value, leaving a long-term development space; On the other hand, China's stock market is still immature. Investors think that there will be a risk of falling for highpriced stock. There is a chance for lower stock price to rise, resulting in a situation in which low-priced stocks are sought after. Moreover, the investment threshold for high-priced stock is high and they cannot meet the investors' needs. But what factors influence the stock price? Why M\&A makes the stock price distribution change?

\subsection{Relationship between Stock Price and Fundamentals before and after M\&A}

This paper introduces fundamentals factors to analyze its relationship with stock prices, and explains the reasons for changes in stock prices before and after M\&A. Select three indicators of earnings per share, cash flow per share, and net assets per share as the fundamentals factors. Earnings per share reflects the company's operating results which investors and other information users evaluate the company's profitability, forecast the company's growth potential, and then make relevant economic decision by it; cash flow per share is an important assessment of earnings per share "gold content" indicator; Net assets per share is one of the most important indicators of the company's intrinsic value. Use the panel data model to estimate fundamentals and stock price:

$$
\begin{gathered}
F_{\mathrm{it}}=\beta_{0}+\beta_{1} E P S_{i t}+\beta_{2} N A P S_{i t}+\beta_{3} N C F_{i t}+\mu_{i t} \quad i=1,2,3 \ldots, M ; \mathrm{t}=1,2,3 \ldots, \mathrm{N} ; \\
\mu_{i t}=T_{i}+E_{t}+\varepsilon_{i t}
\end{gathered}
$$

Among them, $F_{i t}$ is the stock prices of i company on $\mathrm{t}$ day, $E P S_{i t}$ is the earnings per share, ${ }^{\prime} A P S_{i t}$ is the net assets per share, $N C F_{i t}$ represents cash flow per share, $\beta$ is the coefficient, $\mu_{i t}$ represents the errors terms, $T_{i}$ is the company's heterogeneity error terms including factors such as company size, shareholding ratio, managerial ability, and political connections, $E_{t}$ expresses the time effect error terms, including financial crisis, etc., $\varepsilon_{i t}$ is the purely error terms. Both the stock price and the indicators data are unbalanced panel data, and the two-way random effects model cannot be implemented. Based on mixed regression model, fixed effect model and random effects model after regression, the random effects model Hausman test $\mathrm{P}$ value was 0.011 and 0.000 before M\&A, and was 0.000 and 0.000 after M\&A. Reject random model assumptions and using fixed effect model; After the F-test of the mixed regression model and the fixed-effect model, the fixed-effect model was selected, and the mixed-regression model was rejected; The P-value in LR test of the variable coefficient fixed effect model and variable intercept fixed-effects model were both 0.000 , and the two-way fixed effect model was selected, means $T_{i}$ and $E_{t}$ are constants. The results are shown in Table 2.

Table 2. Stock price - fundamentals two-way fixed effect model

\begin{tabular}{lccccc}
\hline Coefficient & $\beta_{0}$ & $\beta_{1}$ & $\beta_{2}$ & $\beta_{3}$ & $\mathrm{R}^{2}$ \\
\hline Pre-merger coefficient & 11.992 & 0.829 & 1.283 & 0.187 & 0.806 \\
Pre-merger P-value & 0.000 & 0.000 & 0.000 & 0.000 & \\
After-merger coefficient & 11.501 & 0.962 & 0.952 & 0.060 & 0.855 \\
After-merger P-value & 0.000 & 0.000 & 0.000 & 0.000 & \\
\hline
\end{tabular}

As can be seen from Table 2, the three fundamentals indicators can significantly explain the stock price, and the indicators have a positive correlation with the stock price. The earnings per share and net assets per share have a greater impact, and the cash flow per share has a small impact. If the company aims to increase stock price, attention should be paid to the net assets per share. It was found that the fundamentals' explaination to stock price increased by $5 \%$ after M\&A than before. The positive impact of earnings per share increased and the net assets per share and cash flow per share impact decreased. Finally, the stock price tends to fluctuate fundamentally after M\&A. Because investors are more optimistic about the growth potential and future profitability of M\&A companies. The reasons for changes in stock prices after M\&A are closely related to changes in the stock price-fundamentals relationship. From the previous analysis, it can be seen that the fundamentals can explain the stock price significantly. Is its distribution and change similar to the stock price?

\subsection{Zipf Distribution of Fundamentals before and after $M \& A$}

The company's fundamentals are estimated using an individual fixed-effects model that eliminates time-effect errors. It represents $E_{t}=0$, and: 


$$
\tilde{Y}_{i t}=\hat{\beta}_{0}+\hat{T}_{i}+\hat{\beta}_{1} E P S_{i t}+\hat{\beta}_{2} N A P S_{i t}+\hat{\beta}_{3} N C F_{i t}
$$

Apply complementary cumulative distribution function to estimate the fundamentals and obtain a Zipf plot. From Figure 4 and 5, it can be seen that the fundamentals also follow the Zipf's law and has a distribution the same as the stock price. The power indexes are 0.490 and 0.505 . It can be seen that the distribution of the stock price is determined by the fundamentals distribution, and the fluctuation is also affected by the fundamentals.

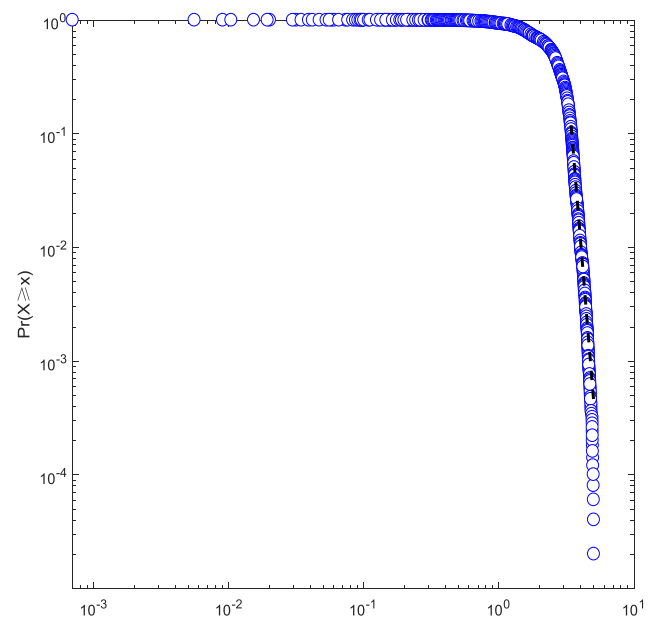

Figure 4. The CCD of Fundamentals before M\&A

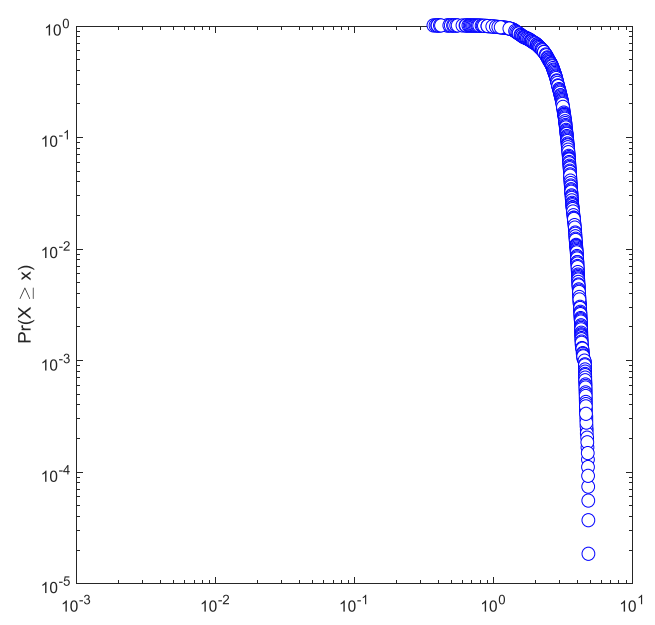

Figure 5. The CCD of Fundamentals after M\&A

Zipf tests were performed on the results and the results shown in Table 4.

Table 4. Fundamentals distribution test results before and after M\&A

\begin{tabular}{ccccc}
\hline$\alpha$ & Crmer-vonMise(p-value) & K-S(p-value $)$ & L-M(p-value $)$ & L-R(p-value $)$ \\
\hline 0.490 & 0.183 & 0.000 & 0.002 & 0.000 \\
0.505 & 0.189 & 0.000 & 0.001 & 0.000 \\
\hline
\end{tabular}

From the results, we can see that the fundamentals before and after M\&A follow Zipf's law, and the difference in power law indexes is very small. The complementary cumulative distribution graphs are similar in shape. All of them pass the power law test and Zipf test, verifying the reason why the stock price follows Zipf. At the same time, the complementary cumulative distribution functions for the three indicators were found to be slightly different, but they all still follow the Zipf distribution law, which can also explain why the fundamentals follow Zipf's law. M\&A did not change the overall distribution of the company's stock price and intrinsic value. So why did it lead to a closer relationship between the two? There are more than half of state-owned enterprises in multinational M\&A companies and the development momentum of each company is relatively good. The investor's expectations are highly compatible with the intrinsic value of companies and the investing value is high. However, from the complementary cumulative distribution graphic, one can intuitively realized is the existence of the 20/80 law. The company is highly heterogeneous with large differences in overall fundamentals. Managerial competencies, employee quality, company size, political relevance and company culture (Chunding, 2009; Yuehui, 2013; Jianquan, 2017) are the reasons for this phenomenon. Listed companies should pay attention to the influence of heterogeneity and fully enhance the company's image.

\section{Conclusion}

This paper builds the SF-DEM model based on Zipf's law, and analyzes the A-share listed companies'multinational M\&A from 2003 to 2016. Use the model of complementary cumulative distribution of stock price and fundamentals and two-way fixed effect model to deepen the relationship between stock price and fundamentals and their changes. The study found that stock price and fundamentals both follow the Zipf's law and are in line with the 20/80 law; After the M\&A, the stock price is more closely related to the fundamentals. The fundamentals can explain $85 \%$ of the stock price changes and increase 5\% compared to it before M\&A. It can be seen that the investors' expectations are in line with the intrinsic value of multinational M\&A companies. The net assets per share and earnings per share have a great impact explaining that investors are optimistic about 
the growth potential and future profitability of M\&A companies. Companies should pay more attention to the growth of these two indicators. Compared before $M \& A$ with after, the overall stock price and fundamentals have improved. Investors expect that multinational M\&A will bring synergies to the companies, shareholder values will increase and state-owned enterprises' multinational M\&A will have national policies and financial support, development and integration will be faster. Other companies will use the advantages of two kinds of resources in the two markets to produce economies of scale, which will increase market share, and eventually increase the value of the company; Because investors expect that the growth of high-priced stock is worse than that of low-priced stock and the high-priced stocks have a higher threshold, they believe that there will be a risk of falling in high-priced stock. There is a chance for stock which prices are lower, resulting in low-priced stock being sought after, and high-priced stocks' changing hands are in the low situation. Multinational M\&A are expected as the good news and performed that the impact on high-priced stock is small and short, the impact on low-priced stock is large and long-lasting. High-priced stock companies should accelerate the pace of dividend payouts to attract more investors' attention.

\section{References}

Ankang, D. (2003). Empirical Analysis of the Return Characteristics of Shanghai Stock Exchange Index. Statistics and Decision, (6), 76-77. https://doi.org/10.3969/j.issn.1002-6487.2003.06.047

Bill, B., \& Francis, I. H. (2007). Financial Market Integration and the Value of Global Diversification: Evidence for US Acquirers in M\&A. Journal of Banking \& Finance, (8), 1522-1540. https://doi.org/10.1016/j.jbankfin. 2007.10.013

Chunding, L. (2009). Research on the Path Choice of Enterprises' Internationalization-New Trade Theory and Its Application in China. Fudan University. https://doi.org/10.3969/j.issn.0488-6364.2010.01.008

Cunha, C. R. (1995). Characteristics of WWW Client-based Traces. Cas Computer Science Technical Reports, 1995. Retrieved from https://hdl.handle.net/2144/1571

Guangzhou, W. (2017). Empirical Study on the Power-law Distribution of Urban Size in China. Economic Geography, (1), 59-65.

Jeffrey, S. A., \& Brian, J. B. (1997). Fundamentals Analysis, Future Earnings, and Stock Prices. Journal of Accounting Research, (1), 1-24. https://doi.org/10.2307/2491464

Jianquan, G. (2017). M\&A experience, political risk and diversified M\&A. Journal of Harbin University of Commerce (Social Science Edition), (4), 34-41.

Julian, di G., \& Andrei, A. L. (2013). Firm entry, trade, and welfare in Zipf's world. Journal of International Economics, (89), 283-296. https://doi.org/10.1016/j.jinteco.2012.08.002

Jun, W. (2007). The Zipf-image and its statistical characteristics in the daily closing price of the stock market. Statistics \& Consulting, (6), 42-43.

Lada, A. A., \& Bernardo, A. H. (2002). Zipf's law and the Internet. Glottometrics, (3), 143-150.

Li, W. (1992). Random Texts Exhibit Zipf's-law-like Word Frequency Distribution. IEEE Transactions on Information Theory, (6), 1842-1845. https://doi.org/10.1109/18.165464

Lihong, R. (2016). Research on the Relationship among Cognitive Conflict, Emotional Conflict and Cultural Integration after Multinational M\&A. Statistics and Decision, (5), 186-188. https://doi.org/10.13546/j.cnki.tjyjc.2016.05.049

Louis, K. C. C.,Yasushi, H., \& Josef, La. (1991). Fundamentalss and Stock Returns in Japan. The Journal of Finance, (5), 1739-1764. https://doi.org/10.1111/j.1540-6261.1991.tb04642.x

Nam-Hoon, K., \& Sara, J. (2000). M\&A:Their Role in Industrial Globalisation. OECD Publising, (1). https://doi.org/10.1787/18151965

Refet, S. G. (2008). Econometric Tests of Asset Price Bubbles: Taking Stock. Journal of Economic Surveys, (1), 166-186. https://doi.org/10.1111/j.1467-6419.2007.00530.x

Robert L. A. (2001). Zipf Distribution of U.S. Firm Sizes. Science, (293), 1818-1820. https://doi.org/10.1126/science.1062081

Shengjiu, L. (2015). Zipf's Law and Webometrics. Chinese Journal of Information, (4), 89-94. https://doi.org/10.3969/j.issn.1003-0077.2015.04.012

Shuyun, C. (2011). Empirical Research on the Influence of fundamentals Factors on the A Share Price 
Movement. Journal of Guizhou University of Economics, (4), 33-36. https://doi.org/10.3969/j.issn.1003-6636.2001.04.009

Taisei, K., \& Michiyo, K. (2004). Power law for ensembles of stock prices. Physica A: Statistical Mechanics and its Applications, (1), 240-243. https://doi.org/10.1016/j.physa.2004.06.125

Wenxia, X. (1986). Zipf's Law and Chinese word frequency distribution mechanism. Information Science, (1), 29-36.

Xavier, G. (1999). Zipf's Law for Cities: an Explanation. The Quarterly Journal of Economics, (3), $739-767$. https://doi.org/10.1162/003355399556133

Xi, C. (2011). Analysis on Regression of Stock Price to Listed Companies Based on Genetic Neural Network. $\begin{array}{llll}\text { Science Technology } & \text { End }\end{array}$ https://doi.org/10.3969/j.issn.1671-1815.2011.27.049

Xiaoting, X. (2004). Comparative Analysis of the Causes of M\&A between China and the United States. Finance and Trade Economy, (6), 90-92.

Xinjian, S. (2012). Strategic Goal and Performance of Chinese Enterprises' Multinational M\&A. World Economy, (5), 81-105.

Yuehui, C. (2013). Research on the influence of knowledge relevancy and knowledge integration ability on the performance of multinational $M \& A$ knowledge transfer. Jilin University.

Yujian, L. (2005). Zipf's law that may exist in protein sequence. Journal of Beijing University of Technology, (4), 366-368. https://doi.org/10.3969/j.issn.0254-0037.2005.04.007

Ziyuan, Z. (2010). Research on the Relationship between Stock Price Volatility and Corporate Fundamentals Risk in China's Listed Companies. Exploration of Economic Issues, (6), 94-99. https://doi.org/10.3969/j.issn.1006-2912.2010.06.018

\section{Copyrights}

Copyright for this article is retained by the author(s), with first publication rights granted to the journal.

This is an open-access article distributed under the terms and conditions of the Creative Commons Attribution license (http://creativecommons.org/licenses/by/4.0/). 